\title{
Assessment of Near-field Pollutant Dispersion: Effect of Upstream Buildings
}

\author{
M. Chavez ${ }^{a^{*}}$, B. Hajra ${ }^{\text {a }}$, T. Stathopoulos ${ }^{\text {a }}$ A. Bahloul ${ }^{b}$ \\ a Department of Building, Civil and Environmental Engineering, Concordia University, \\ Montreal, Canada \\ bInstitut de recherche Robert-Sauvé en santé et en sécurité du travail, Montreal, Canada \\ *Corresponding email: mau_chav@encs.concordia.ca
}

\section{ABSTRACT}

The prediction of pollutant dispersion in urban environment is an extremely complex phenomenon, particularly in the vicinity of a cluster of buildings. Dispersion of effluents released from stacks located on building roofs are severely affected by adjacent surroundings. This paper investigates the impact of an upstream building on the near field of a pollutant source in terms of dilution distribution on the roof of an emitting building. The study was carried out using Computational Fluid Dynamics (CFD) approach with Realizable $k$ - $\varepsilon$ for turbulent flow modeling. A limited number of cases were also modelled in a wind tunnel for validation purposes. The study shows that when the source is located within the recirculation zone, dilution is highly sensitive to the height of the upstream building and much less sensitive to the width and length of the upstream building. It is also shown that dilution value has an asymptotic behavior which defines the particular point where dilution becomes independent of the upstream building configuration. Some discrepancies between CFD and wind tunnel data were found, specifically for extreme configurations e.g. significantly taller upstream building. These differences are mainly due to the inherent unsteady fluctuations in the wake of buildings which are not detectable by RANS.

\section{INTRODUCTION}

Air quality in urban areas has gained increasing interest in recent years due to its significant influence in human health. In 2004, Health Canada estimated that air pollution caused nearly 6000 premature deaths each year in 8 cities in Canada (Judek et al., 2004). The Canadian Medical Association extended this study and estimated that approximately 21000 deaths could be attributed to air pollution in 2008 in the entire country. The air pollution has a wide range of effects, with 
chronic respiratory diseases and loss of life the most serious; however this problem carries also high economical damage including lost productivity, life quality degradation and health care costs, which have been estimated to $\$ 8$ billion (CMA, 2008).

In the built environment increasing exhaust emissions from institutional, industrial buildings and vehicular traffic are inevitable. Toxic and odorous emissions affecting the urban environment and degrading human health are present in every city. One on the most common urban pollution phenomenon is associated with contaminants released from rooftop stacks. Depending on the average airflow, the turbulence of flow and the building-generated turbulence, pollutants can be trapped in recirculation zones and affect sensitive areas as, for example, fresh air intakes. This closed circuit path is known as re-ingestion of pollutants.

In a dense urban area there is plenty of opportunity for re-ingestion and the health impact of this episodic pollution event is a cause for concern for health physicists and regulatory agencies. Unfortunately, the state of art is not sufficiently advanced to allow building engineers to apply appropriate design criteria to avoid this problem for new construction or to help alleviate the re-ingestion of pollutants for existing buildings. Consequently, incidents involving poor air quality continue to be recorded and documented.

Complexities in airflow and pollutant transport due to terrain conditions, local topography and buildings make it very difficult to assess plume concentrations (Saathoff et al., 2009). This study will focus on the effect of an upstream building on dispersion in the immediate vicinity of the source of pollutant. Four different upstream configurations have been tested in the Boundary Layer Wind Tunnel of Concordia University, Canada and compared with earlier results for an isolated building case. In particular, the impact of plume dilutions on the change in height, along wind and across wind dimensions of the upstream building were studied. In the past, studies performed by Wilson et al. (1998) and Stathopoulos et al. (2008) showed that the presence of a taller upstream building produces higher concentrations on the rooftop of the emitting building. Currently, ASHRAE (2007) gives guidelines for determining plume dilutions for an isolated building, i.e. without considering the effects of adjacent buildings and local turbulence. Studies performed by Hajra et al. (2010) have shown that ASHRAE (2007) predicts rather unrealistic and overly conservative dilutions. More recently, Computational Fluid Dynamics (CFD) has been a useful tool in assessing plume dilutions in the built environment. However, CFD simulations require validations with field and wind tunnel measurements. 
This paper presents wind tunnel data for tracer gas released from a rooftop stack in the presence of upstream buildings for stack height of $0.005 \mathrm{~m}$ (full scale equivalent to $1 \mathrm{~m}$ ) at exhaust momentum ratio $\mathrm{M}$, defined as the ratio between the exhaust velocity $\left(\mathrm{V}_{\mathrm{e}}\right)$ and wind velocity at the building height $\left(\mathrm{U}_{\mathrm{B} 1}\right)$, equal to 1 . The spacing between the buildings was fixed to $0.1 \mathrm{~m}(20 \mathrm{~m})$ and the stack location was $0.1 \mathrm{~m}(20 \mathrm{~m})$ from the upwind edge of the emitting building. Results are compared to CFD simulations using the Realizable $k$ - $l$ model (Shih et al., 1995) for different turbulent Schmidt numbers $\left(\mathrm{Sc}_{\mathrm{t}}\right)$ and dilution from ASHRAE (2007).

\section{WIND TUNNEL SETUP}

81

The wind tunnel experiments were carried out in the open circuit of the Building Aerodynamics boundary layer wind tunnel Laboratory at Concordia University, Montreal, Canada. The wind tunnel is $1.8 \mathrm{~m}$ by $1.8 \mathrm{~m}$ in cross-section and $12.2 \mathrm{~m}$ in length. The buildings tested in the wind tunnel were made of timber on a 1:200 scale. According to Snyder (1981) while modeling non-buoyant plume exhaust, certain criteria should be satisfied:

87

- Geometric similarity

- Building Reynolds Number $>11000$

- $\quad$ Stack Reynolds Number $>2000$

- Similarity of wind tunnel flow with that in atmospheric surface layer

- Equivalent stack momentum ratio.

Tracer gas consisting of a mixture of Sulphur hexafluoride $\left(\mathrm{SF}_{6}\right)$ and Nitrogen was released from a roof stack of an emitting building named B1. A multi-syringe pump was used to collect the gas samples to determine the concentration of effluents at various receptors with a sampling time of 1 minute. A Gas Chromatograph (GC) was used to assess the gas concentrations that were collected using syringe samplers. The velocity at building height was measured to be $6.2 \mathrm{~m} / \mathrm{s}$ in the wind tunnel. The buildings were considered to be in an urban terrain with a power law exponent of 0.31

100 (Simiu and Scanlan, 1996). Additional details on the experimental conditions used in this study are described in Stathopoulos et al. (2008). 
103 The pollutant dispersion was evaluated in terms of normalized dilution following the formulation suggested by Wilson (1979):

105

$\mathrm{D}_{\text {Normalized }}=\left(\mathrm{D}_{\mathrm{r}} \mathrm{Q}\right) /\left(\mathrm{U}_{\mathrm{B} 1} \mathrm{H}_{\mathrm{B} 1}{ }^{2}\right)$

where $D_{r}=C_{e} / C_{r}$ is the dimensionless concentration coefficient at the coordinate location (receptor $), \mathrm{C}_{\mathrm{e}}=$ contaminant mass fraction in exhaust $(\mathrm{ppm}), \mathrm{C}_{\mathrm{r}}=$ contaminant mass fraction at the coordinate location (ppm), $\mathrm{Q}$ is the flow rate at the exhaust $\left(\mathrm{m}^{3} / \mathrm{s}\right), \mathrm{H}_{\mathrm{B} 1}$ is the height of the emitting building called $\mathrm{B} 1\left(\mathrm{H}_{\mathrm{B} 1}=0.075 \mathrm{~m}\right)$, and $\mathrm{U}_{\mathrm{B} 1}$ the wind speed at $\mathrm{H}_{\mathrm{B} 1}\left(\mathrm{U}_{\mathrm{B} 1}=6.2 \mathrm{~m} / \mathrm{s}\right)$. The ratio at the stack outflow is $M=V_{e} / U_{B 1}$ (where $V_{e}$ is the exhaust velocity).

Figure 1 shows the emitting building B1 receptor locations. Dilution concentration measurements were carried out using receptors ( 4 upwind and 6 downwind the stack) located centrally on the rooftop of B1 and spaced $0.025 \mathrm{~m}$ apart and $0.125 \mathrm{~m}$ from lateral edges. Receptors were located on rooftop primarily due to the plume trajectory in the presence of an upstream building, as discussed

118 further in Wilson et al. (1998), and for direct comparisons with the ASHRAE (2007) dispersion 119 model.

\section{Figure 1}

Five building models were used to generate four different upstream configurations. The dimensions of each building used in the study are provided in Table 1 with a generic schema of configurations shown in Figure 2.

\section{Table 1}

The following configurations were simulated in the wind tunnel 


\section{NUMERICAL SIMULATION}

\subsection{Computational model and boundary conditions}

143 CFD is a useful tool for simulation of turbulent flow and pollutant dispersion around buildings. 144 The present work was carried out using the commercial software FLUENT based on the ReynoldsAveraged Navier-Stokes equations (RANS). The effects of different turbulence models have been tested in previous flow field around bluff bodies (Yap, 1987; Launder and Kato, 1993; Tsuchiya et al., 1997, Tomigana and Stathopoulos, 2009); however a clear statement about the optimum choice of turbulence model for flow around buildings is still not available. The reason is because turbulence models performance depends on the particular case. This paper uses the Realizable $k-\varepsilon$ turbulence model based on a literature review carried out by the authors in a previous work (Chavez et al. 2011). All the transport equations (momentum, energy, $k, \varepsilon$ and concentration) were discretized using a second-order upwind scheme. Pressure interpolation was of second order. The SIMPLE algorithm was used for pressure-velocity coupling.

Based on recommendations proposed in COST Action (Franke et al., 2007), the dimensions of the computational domain were specified as follows: considering $\mathrm{H}$ as the height of the taller building in the model, the lateral and the top boundary was located $5 \mathrm{H}$ away from the building and the outlet boundary was $20 \mathrm{H}$ downwind from the building to allow flow development. For the inlet a distance of $3 \mathrm{H}$ was adopted in order to minimize the development of streamwise gradients, as discussed in Blocken et al. (2007).

The numerical model was constructed principally using structured hexahedra grids since it has

163 been proved that this mesh style provides the best computational results (Hefny and Ooka, 2009).

164 In order to reduce the mesh size and considering that all the physical simulations were performed for a unique wind flow (perpendicular to the building face) a symmetry boundary condition was applied at half width of the emitting building, in consequence all calculations correspond to half domain only, see Figure 2. This consideration was verified by comparison with a full domain simulation. Due to the circular section of the stack, an unstructured wedge grid was used in its vicinity. The grid size used in the current work is based on a grid sensitivity analysis performed by the authors in a previous work (Chavez et al., 2011) since dimensions of models and characteristics of 
171 pollutants emission remain very similar. In the current work the number of cells was approximately 600,000 to 800,000 depending on the configuration. The grid resolution was $0.001 \mathrm{~m}$ at the stack and $0.005 \mathrm{~m}$ at the edges of the emitting building and increased gradually to $0.0346 \mathrm{~m}$ at the limit of domain.

The bottom surface (i.e ground) is specified as a rigid plane with an aerodynamic roughness length $\mathrm{y}_{\mathrm{o}}=0.0033 \mathrm{~m}$ corresponding to $\mathrm{y}_{\mathrm{o}}=0.66 \mathrm{~m}$ in full scale. In FLUENT this roughness length is implemented by the sand-grain roughness height $\mathrm{k}_{\mathrm{s}}(\mathrm{m})$, defined using the function developed by Blocken et al. (2007): $\mathrm{k}_{\mathrm{s}}=9.793 \mathrm{y}_{\mathrm{o}} / \mathrm{Cs}$, where $\mathrm{Cs}$ is a roughness constant. Considering the default value of Cs equal to $0.5, \mathrm{k}_{\mathrm{s}}$ should be specified as 0.0646 . However, this value is limited to the distance $z_{p}$ of the centroid of the first cell to the bottom domain (in this case $z_{p}=0.00187 \mathrm{~m}$ ), as imposed by FLUENT. The effect of this limitation is translated to stream wise changes in the inlet vertical profile, which attempts to improve the accuracy of CFD simulations. This issue has been discussed in previous works (Hargreaves and Wright, 2007; Norris and Richards, 2010; Parente et al., 2011a, 2011b). To reduce the effect of undesired inlet profile, the current study has adopted the minimization of upstream domain length criterion by specifying $3 \mathrm{H}$ (as mentioned previously) as suggested by Blocken et al. (2007). This option is reasonable in the present case considering that the wind flow impinging the plume is more affected by the presence of the upstream building than the roughness length.

The approaching mean velocity and turbulence intensity profiles measured in the wind tunnel and used to specify the inlet boundary layer at the CFD model are shown in Figure 3. Similar to the experiment, a power law exponent of 0.31 corresponding to urban terrain was used for the study. The velocity at the building $\mathrm{B} 1$ height $(\mathrm{H}=0.075 \mathrm{~m})$ was $\mathrm{U}_{\mathrm{B} 1}=6.2 \mathrm{~m} / \mathrm{s}$. The turbulent kinetic energy profile $(k)$ was calculated using $k=0.5\left(\mathrm{I}_{\mathrm{U}} \mathrm{U}\right)^{2}$ and turbulent intensity values $\left(\mathrm{I}_{\mathrm{U}}\right)$ measured in the current wind tunnel experiments. The dissipation rate profile $(\varepsilon)$ was defined as $\varepsilon=\mathrm{u}^{* 3} / \kappa y$ where $\kappa$ is the von Karman constant $(0.42)$ and $\mathrm{u}^{*}$ is the friction velocity obtained from the equation $\mathrm{u}(\mathrm{y}) / \mathrm{u}^{*}=1 / \kappa\left(\ln \left(\mathrm{y} / \mathrm{y}_{\mathrm{o}}\right)\right.$ with roughness length $\mathrm{y}_{\mathrm{o}}=0.0033 \mathrm{~m}$. Top and sides of the domain were modelled as slip walls (zero shear slip). At the outlet an outflow (zero gradient) condition was specified, to generate a fully developed flow. For walls, the standard wall function was applied because $\mathrm{y}^{*}$ was between 30 and 300 in a large number of cells. A symmetry boundary condition was added at half of the emitting building, as explained previously. The pollutant released from stack was simulated with $\mathrm{SF}_{6}$ for a particular exhaust momentum ratio $\mathrm{M}=\mathrm{V}_{\mathrm{e}} / \mathrm{U}_{\mathrm{B} 1}=1$ (where $\mathrm{V}_{\mathrm{e}}$ is the exhaust velocity). 
Figure 3

208 Turbulent $\mathrm{Schmidt}$ number $\left(\mathrm{Sc}_{\mathrm{t}}\right)$ is necessary to solve the transport mass equation in CFD predic209 tion of dispersion with RANS and is defined as the ratio of turbulent momentum diffusivity (eddy 210 viscosity) to the turbulent mass diffusivity $\left(\mathrm{Sc}_{\mathrm{t}}=\mathrm{v}_{\mathrm{t}} / \mathrm{D}_{\mathrm{t}}\right)$. In FLUENT $\mathrm{Sc}_{\mathrm{t}}$ must be declared as input 211 prior to any calculation or else the default value assumed is 0.7. Past studies have shown the de212 pendence of $\mathrm{Sc}_{\mathrm{t}}$ on simulation of pollutant dispersion from isolated buildings (Tominaga and 213 Stathopoulos, 2007; Chavez et al., 2011) and hence the present work pays special attention to $\mathrm{Sc}_{\mathrm{t}}$ 214 values

\section{RESULTS AND DISCUSSION}

217

218 A qualitative comparison between experimental and numerical simulations for dilution on the roof 219 of the emitting building is presented. Several configurations were evaluated and a single wind tunnel measurement for each case was used to make a comparison with CFD. The confidence (or repeatability) of this single measurement was assumed to be within $10 \%$, as it was found by Stathopoulos et al. (1999) where the same wind tunnel with similar flow characteristics was used. Quantitative analysis for every comparison as the quantitative metric proposed by Oberkampf and Barone (2006) has not been used in the presented study.

\subsection{Isolated building}

Figure 4 shows the dilution comparison between wind tunnel measurements, $\mathrm{CFD}$ for $\mathrm{Sc}_{\mathrm{t}}=0.3,0.7$ and ASHRAE (2007). The wind tunnel data correspond to measurements performed in July 2009 (Chavez et al., 2011). The dilution values upstream the stack were too high to be detected by the chromatograph used in the tests, so data to be compared with CFD are not available. Concerning the dilution comparison between CFD and experimental data, it is clearly demonstrated that RANS underestimates dilution when using standard values of $\mathrm{Sc}_{\mathrm{t}}\left(\mathrm{Sc}_{\mathrm{t}}=0.7\right)$ for an isolated building case.

234 This observation was also pointed out in previous studies (Tominaga and Stathopoulos, 2007;

235 Chavez et al., 2011). The reason is mainly due to the weakness of RANS to modeling turbulent 236 diffusion in zones with flow separation, as is the case on the roof of an isolated building. To cali237 brate this underestimation a correct parametrization of turbulent fluxes via the $\mathrm{Sc}_{\mathrm{t}}$ is required 
238 (Gousseau et al., 2011). Modification of $\mathrm{Sc}_{\mathrm{t}}$ will influence the spread of pollutant deficiently predicted by RANS. In this case, dilution calculated by CFD can have acceptable agreement with

240 experimental values by using $\mathrm{Sc}_{t}=0.3$. It is also observed that dilution model proposed by 241 ASHRAE (2007) predicts very low dilutions, yielding very conservative results.

\section{Figure 4}

\subsection{Effect of upstream building height}

The effect of height of a building placed upstream of B1 is presented in Figures 5, 6, 7 and 8.

248 Figures 5 and 6 show streamlines and normalized dilution field on the middle vertical and horizontal planes at the stack height $(\mathrm{y}=0.08 \mathrm{~m})$ for Config-3 and Config-5. The height of the upstream building was changed keeping its width $(0.25 \mathrm{~m})$ and length $(0.075 \mathrm{~m})$ constant. The spacing between buildings was also kept constant at $0.1 \mathrm{~m}$. Figure 5 shows an extended wake zone with secondary vortices behind the two buildings in the vertical and horizontal plane of Config-3. The vertical plane near the stack shows a combination of upwind and downwind flow. The horizontal velocity plan shows the important cross flow from the side. The dilution contours reveal that part of the pollutants are dragged upwind toward the leeward wall of the upstream building. In consequence, a very long dilution distribution along the middle axis was observed downwind the stack.

\section{Figure 5}

260 Figure 6 shows the vertical and horizontal velocity field and the corresponding dilution contours for Config-5 (a taller upstream building). Clearly the wake zone was larger than the previous case and a strong horizontal vortex (not observed previously) near the roof of the upstream building appears within the recirculation zone. A well-formed vortex between the two buildings is formed with a diameter equal to the distance between the two buildings. The general pattern of flow reveals that the wake is characterized by a predominant horizontal upwind velocity component. The corresponding dilution contours show that practically the entire plume is trapped and dragged toward the leeward of the upstream building. When the pollutants reach the leeward wall, they are immediately transported downstream by the sides following the large horseshoe developed around the buildings. 
273 Figures 7 and 8 show the influence of upstream building height on the velocity profile immediately 274 above the stack and the dilution distribution on the roof of B1. The relative height of the upstream 275 building is identified using the parameter "h" which is the ratio of the upstream building and B1 276 height $\left(h=\mathrm{H}_{\text {upstream }} / \mathrm{H}_{\mathrm{B} 1}\right)$. Figure 7 shows the along wind velocity component (Ux) profile on a 277 vertical line above the stack. As the height of the upstream building increases, the along wind component velocity tends to move in the upwind direction. The local velocities near and above the stack in Config-5 show that the entire flow in this zone is directed upwind. On the other hand, it is observed that in the same zone the entire flow is directed downstream in the same zone for the isolated building case.. The range of maximum velocities are near $3 \mathrm{~m} / \mathrm{s}$ upwind for Config-5 and $9 \mathrm{~m} / \mathrm{s}$ downwind for the isolated building. For configurations in between these two, the wind profile has a combination of components upwind and downwind. As noted in Figure 8, the dilution field is affected by these different local velocities in the wake, especially downstream the stack. In this zone dilution increases as the upstream building height increases following an asymptotic behaviour. This observation suggests that a change of the upstream building height does not affect the dilution downwind the stack after a specific " $h$ " starting near 2.8. On the other hand, dilution distribution upwind the stack seems to be independent of the upstream building height when a critical height, $h_{c}$, between 1.33 and 1.7 , is reached. For values below $h_{c}$, and up to $h=1$, the dilution distribution upwind the stack is extremely dependant on the upstream building height. It can thus be concluded that dilution is very sensitive to the height of upstream buildings in areas downstream the stack, upstream the stack dilution seems to be independent of the upstream building height for values starting from $\mathrm{h}_{\mathrm{c}}$. Experimental and numerical results presented a similar trend, which was characterized by low dilution upwind and high dilution downwind the stack. However, significant quantitative inconsistencies were registered specially for a much taller upstream building (Config-5). This is probably due to the inherent fluctuations in the wake of buildings which are not detectable by RANS. These fluctuations are characterized by unsteady vortical structures which interact with each other and with the surroundings playing a fundamental roll in the transport mechanism of pollutants. In consequence, steady RANS will reproduce unrealistic dilution values in regions where mixing is caused by the advection of generated eddies into the wake. ASHRAE (2007) predicted very low dilutions, yielding very conservative results. 
309 Figures 9 and 10 show the effect of varying width, which is the across wind dimension, of the 310 upstream building; whereas Figures 11 and 12 show the effect of varying length of the upstream 311 building. In general, the effect of these two geometric variables produce somewhat similar behav312 ior with that discussed previously for the building height effect. This is low dilution upwind the 313 stack which is independent to the shape of the upstream building following by dilution that increases along the wind axis for the downwind stack region. The dilution downwind the stack is different depending on the shape of the upstream building, however it should be noticed that the effect is relatively less important for both width and length in comparison with the height effect.

Figures 9 and 10 show the effect of upstream building width in the along wind velocity component (Ux). The relative width of the upstream building is identified using the parameter "w" which is the ratio of the upstream building width and $\mathrm{B} 1$ width $\left(\mathrm{w}=\mathrm{W}_{\text {upstream }} / \mathrm{W}_{\mathrm{B} 1}\right)$. The velocity profile showed a lightly variation for different upstream building width. The corresponding dilution values upwind the stack are almost independent of the upstream building width and has a relatively small influence on dilution downstream the stack. For a larger w value, dilution increases monotonically downwind the stack. This is probably because a larger recirculation vortex on side of B1 may be carrying extra fresh air for dilution. It is also noted that for small upstream building widths, dilution tends to behave as in the case of an isolated building.

\section{Figure 9}

\section{Figure 10}

Figures 11 and 12 show the effects of upstream building length. As with previous cases, "l" represents the ratio of the upstream building length and B1 length $\left(1=\mathrm{L}_{\text {upstream }} / \mathrm{L}_{\mathrm{B} 1}\right)$. As in previous cases, dilution upwind the stack is almost independent of the upstream building length and dilution downwind the stack increases when the length of the upstream building decrease. This could be explained again by the added side recirculation produced by a thin building.

\section{Figure 11}




\section{CONCLUSION}

344 The influence of three variables (height, width and length) of an upstream building on pollutant 345 dispersion in the built environment was examined using wind tunnel experiments and CFD mod346 eling. The dilution of pollutants is affected significantly by the height of the upstream building especially for the region downwind the stack where a direct dependence on the upstream building height was observed. In contrast, dilution shows very little sensibility to all configurations for a region upwind the stack. It is also confirmed that ASHRAE (2007) is too conservative for all cases. CFD simulations show discrepancies on dilution values downwind the stack for an upstream highrise building producing high dilution compared with the wind tunnel. These differences may be explained by the inaccuracy of steady state RANS to capture dispersion in areas of high turbulent flow.

\section{REFERENCES}

ASHRAE, 2007. Building air intake and exhaust design. ASHRAE Applications Handbook, Chapter 44, American Society of Heating, Refrigerating and Air-Conditioning Engineering Inc., Atlanta, USA. problems. Atmos. Environ. 41, 238-252. Medical Association; 2008. Available from: www.cma.ca/multi media/CMA/Content_Images/Inside_cma/ Office_Public_Health/ICAP/CMA_ICAP_sum_e.pdf. Accessed 2011 Jun 13. Chavez, M., Hajra, B., Stathopoulos, T., Bahloul, A., 2011. Near-field pollutant dispersion in the built environment by CFD and wind tunnel simulations. J. Wind Eng. Ind. Aerodyn. 99 (4), 330-339. Franke, J., Hellsten, A., Schunzen, H., Carissimo, B., 2007. Best practice guideline for the CFD simulation of flows in the urban environment. Cost Action 732, Quality assurance and improvement of microscale meteorological models.

370 Gousseau, P., Blocken, B., Van Heijst G.J.F. 2011.CFD simulation of pollutant dispersion around isolated buildings:

371 On the role of convective and turbulent mass fluxes in the prediction accuracy. J. Hazard. Mater. 194, 422-434. 
373 ADMS and wind tunnel simulation. Build. Environ. 45, 2768-2777.

374 Hargreaves, D., Wright, N., 2007. On the use of the $k-\varepsilon$ model in commercial CFD software to model the neutral 375 atmospheric boundary layer. J. Wind Eng. Ind. Aerodyn. 95, 355-369.

376 Hefny, M., Ooka, R.., 2009. CFD analysis of pollutant dispersion around buildings: effect of cell geometry. Build. 377 Environ. 44(8), 1699-1706.

378 Judek, S., Jessiman, B., Stieb, D., Vet, R., 2004. Estimated number of excess deaths in Canada due to air pollution. Ottawa, ON: Health Canada; Available from: www.metrovancouver.org/about/publications/Publications/ AirPollu-

380 tionDeaths.pdf. Accessed 2011 Jun 13.

381 Launder, B.E., Kato, M., 1993. Modeling flow-induced oscillations in turbulent flow around a square cylinder. In 382 ASME Fluid Engineering Conference.

383 Norris, S.E., Richards, P.J., 2010. Appropriate boundary conditions for computational wind engineering models re-

384 visited. In: Proceedings of the Fifth International Symposium on Computational Wind Engineering (CWE2010)

385 Chapel Hill, North Carolina, USA, May 23-27, 1-8.

386 Oberkampf, W. L., \& Barone, M. F. 2006. Measures of agreement between computation and experiment: Validation metrics. J. Comp. Phys., 217(1), 5-36.

388 Parente, A., Gorlé, C., van Beeck, J., Benocci, C., 2011a. Improved $k-\varepsilon$ model and wall function formulation for the 389 RANS simulation of ABL flows. J. Wind Eng. Ind. Aerodyn. 99, 267-278.

390 Parente, A., Gorlé, C., van Beeck, J., Benocci, C., 2011b. A Comprehensive modelling approach for the neutral atmospheric boundary layer: Consistent inflow conditions, wall function and turbulence model. Boundary-Layer Me-

392 teorol. 140, 411-428.

393 Saathoff, P., Gupta, A., Stathopoulos, T., Lazure, L., 2009. Contamination of fresh air intakes due to downwash 394 from a rooftop structure. J. Air Waste Manage. Assoc. 59, 343-353.

395 Stathopoulos T., Lazure L. and Saathoff P. 1999. Tracer gas reingestion of Building Exhaust in an Urban Environ396 ment, IRSST research report R-213 Institut de recherché Robert-Sauvé en santé et en sécurité du travail, Montreal, 397 Canada.

398 Shih, T.H., Liou, W.W., Shabbir, A., Yang, Z., Zhu, J., 1995. A new $k$ - $\varepsilon$ - eddy-viscosity model for high Reynolds 399 number turbulent flows. Comp. Fluids. 24(3), 227-238.

400 Simiu, E., Scanlan, R. H., 1996. Wind effects on structures: fundamentals and applications to design. 3rd Edition, 401 Wiley Interscience Publication, USA. 
402 Snyder, W. H., 1981. Guidelines for fluid modelling of atmospheric diffusion. EPA office of Air quality, planning

403 and standards, Research Triangle Park, USA, EPA-600/8-81-009.

404 Stathopoulos, T., Hajra, B., Bahloul, A., 2008. Analytical evaluation of dispersion of exhaust from rooftop stacks on 405 buildings. IRSST research report R-576, Institut de recherche Robert-Sauvé en santé et en sécurité du travail, Mon406 treal, Canada.

407 Tominaga, Y., Stathopoulos, T., 2007. Turbulent Schmidt numbers for CFD analysis with various types of flowfield. 408 Atmos. Environ. 41, 8091-8099.

409 Tominaga, Y., Stathopoulos, T., 2009. Numerical simulation of dispersion around an isolated cubic building: com410 parison of various types of $\mathrm{k}-\varepsilon$ models. Atmos. Environ, 43, 3200-3210.

411 Tsuchiya, M., Murakami, S., Mochida, A., Kondo, K., Ishida, Y., 1997. Development of a new $k$ - $\varepsilon$ model for flow 412 and pressure fields around bluff body. J. Wind Eng. Ind. Aerodyn. 67\&68, 169-182.

413 Wilson, D.J. 1979. Flow patterns over a flat roofed buildings and application to exhaust stack design.

414 ASHRAETransactions, 85(2), 284-295.

415 Wilson, D. J., Fabris, I, Ackerman M Y., 1998. Measuring adjacent effects on laboratory exhaust stack design.

416 ASHRAE Transactions, 88 (1), 513-533.

417 Yap, C.J., 1987. Turbulent Heat and Momentum Transfer in Recirculating and Impinging Flows. PhD thesis, Uni418 versity of Manchester.

419 
420

421

422

423

424

425

426

427

428

429

430

431

432

433

434

435

436

437

438

439

440

441

442

443

444

445

446

447

448

449

450

451

452

453

454

455

456

457

458

459

460

461

462

463

464

465

466

467

468

469

470

471

472

473

474

475
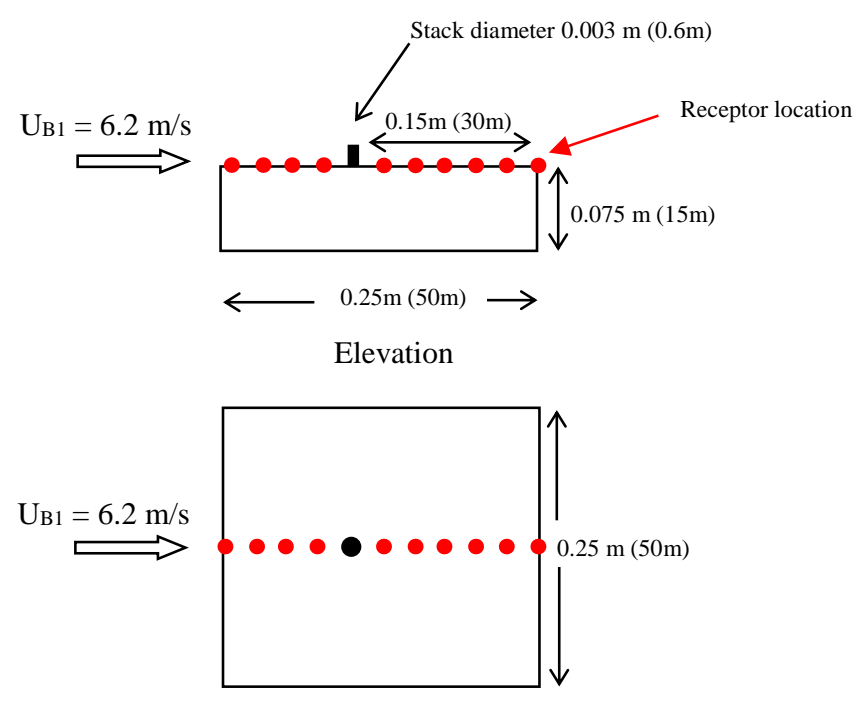

Plan

Figure 1: Elevation and plan view of the emitting building, B1 (wind tunnel model).

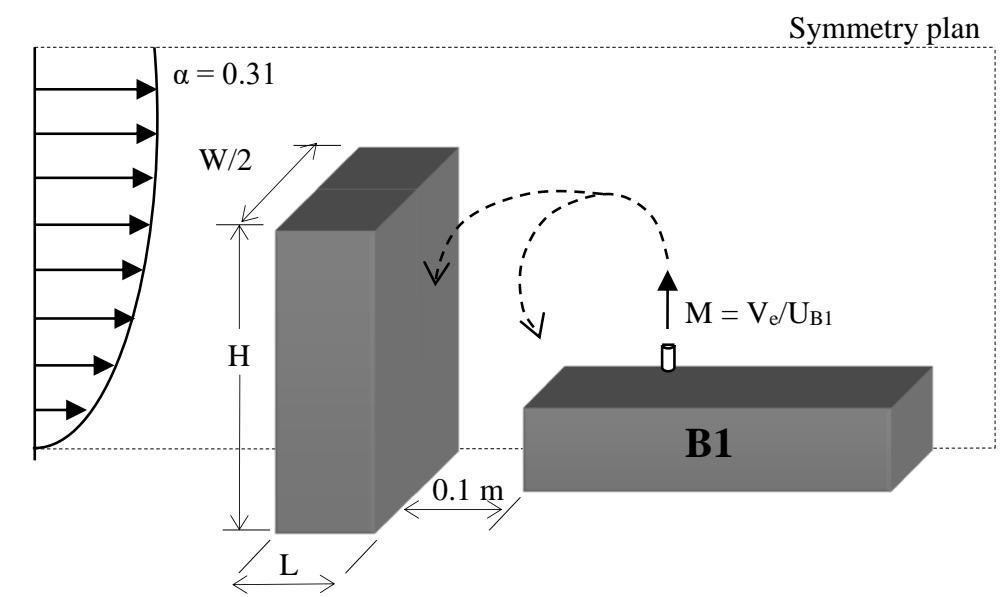

Figure 2: Isometric view of B1 with an upstream building (CFD model) 
476

477

478

479

481

482

483

484

485

486

487

488

489

490

491

492

493

494

495

496

497

498

499

500

501

502

503

504

505 a)

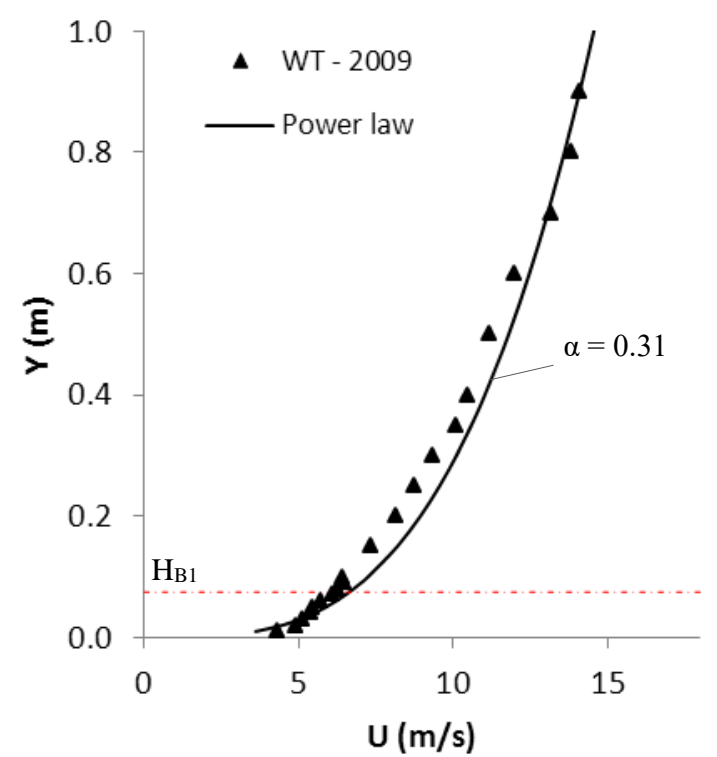

b)

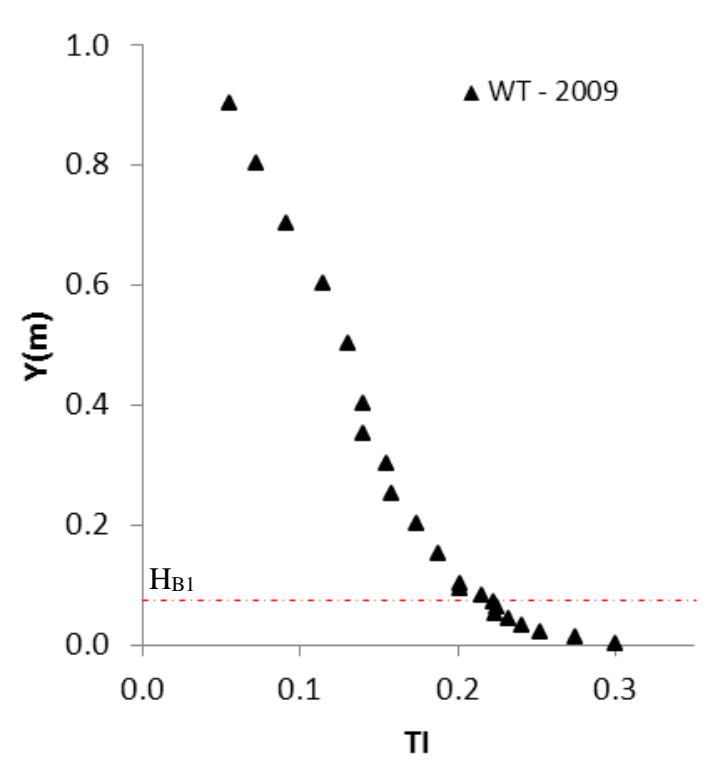

Figure 3: Inlet profile measurements from wind tunnel. a) Velocity profile b) Turbulence intensity. 


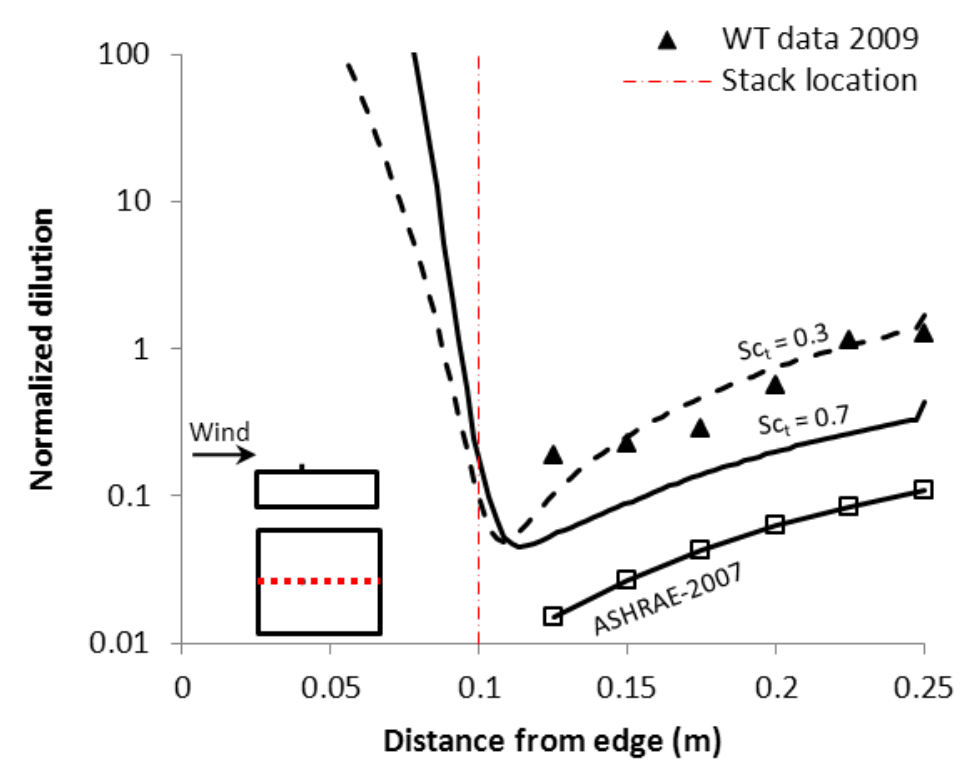

Figure 4. Normalized dilution on isolated building roof, B1, for different $\mathrm{Sc}_{\mathrm{t} .}$ a) 2009 Wind tunnel data and CFD-Realizable k- $\varepsilon$. 
$56^{7}$

56 i

56 !

571

57

57 '트

57 :

57.

57.

$57 \mathrm{t}$

$57^{\circ}$

57 ₹

579

580

581

582

583

584 需

585

586

587

588

589

590

591

592

593

594

59.

59 59.

59 ?

59 '

$600^{\circ}$

60

60 '

60

60

60:

606

607

$60 \varepsilon$

605

$611^{\text {壹 }}$

612

61:

614

615

616

617

618

619

620

621

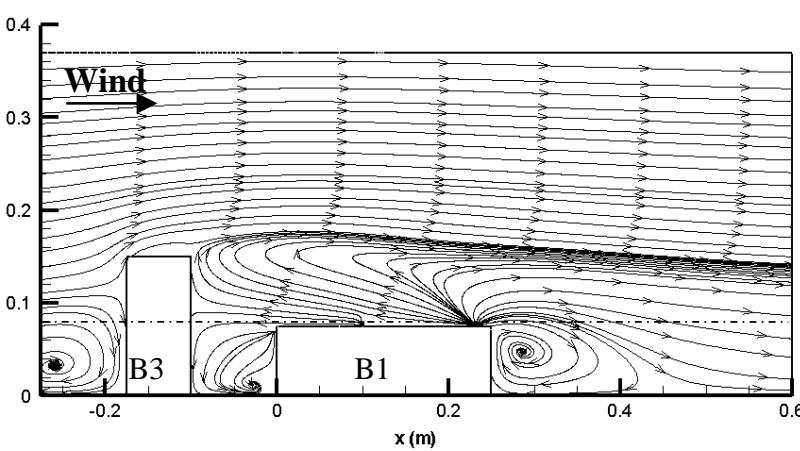

Elevation

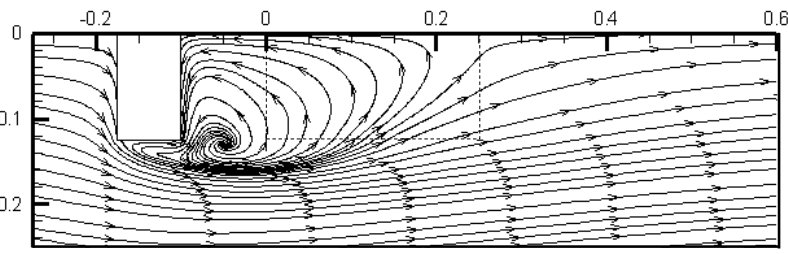

Plan

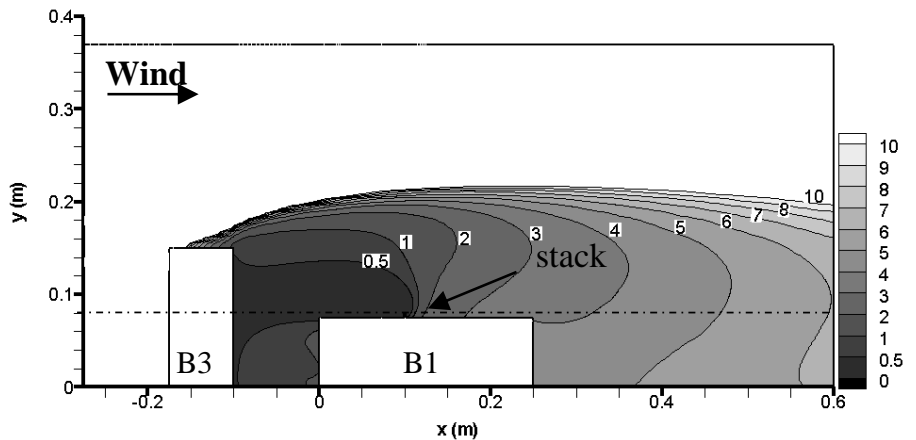

Elevation

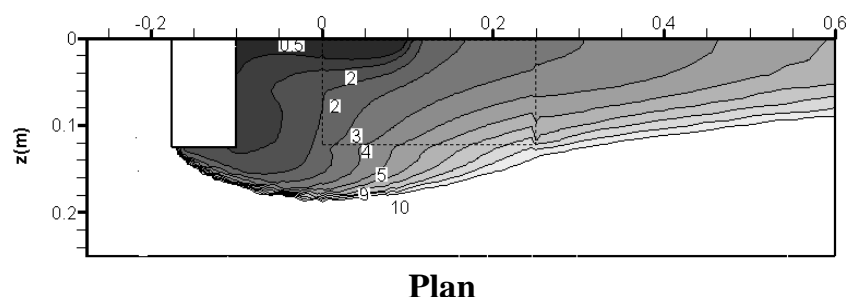

Figure 5. Elevation and half plan view (at $\mathbf{H}=\mathbf{0 . 0 8} \mathrm{m}$ ) of streamlines and dilution contours of Config-3. $\mathrm{Sc}_{\mathrm{t}}=\mathbf{0 . 7}$. Dilution scale from 0-10.

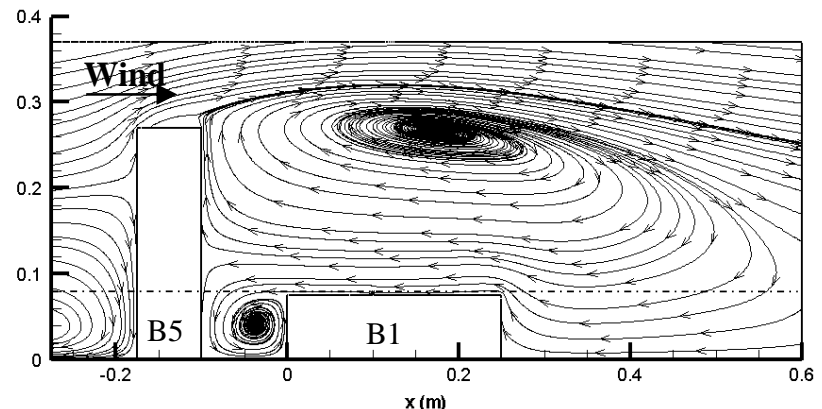

Elevation

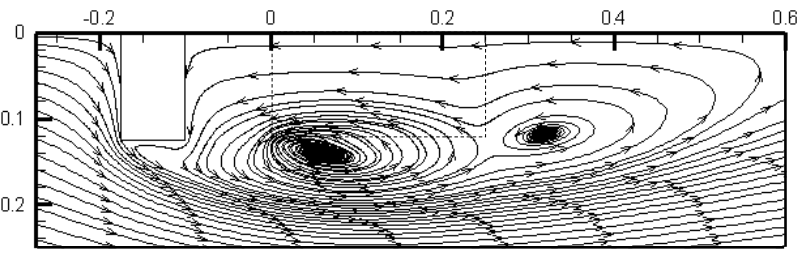

Plan

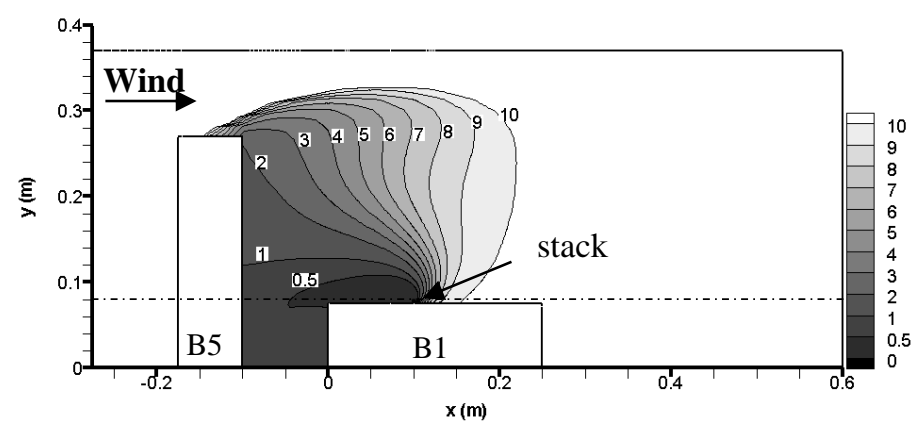

Elevation

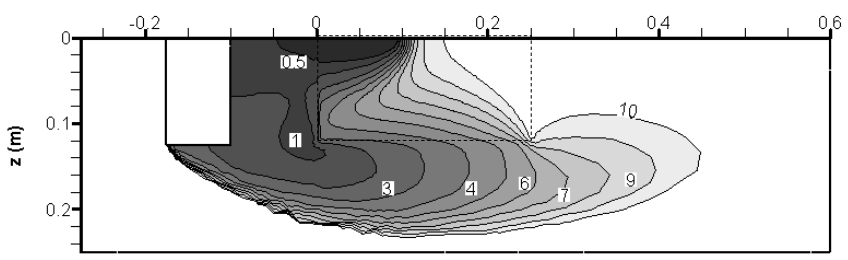

Plan

Figure 6. Elevation and half plan view (at $\mathbf{H}=0.08 \mathrm{~m}$ ) of streamlines and dilution contours of Config-5. $\mathrm{Sc}_{\mathrm{t}}=\mathbf{0 . 7}$. Dilution scale from 0-10. 
657

658

659

660

661

662

663

664

665

666

667

668

669

670

671

672

673

674

675

676

677

678

679

680

681

682
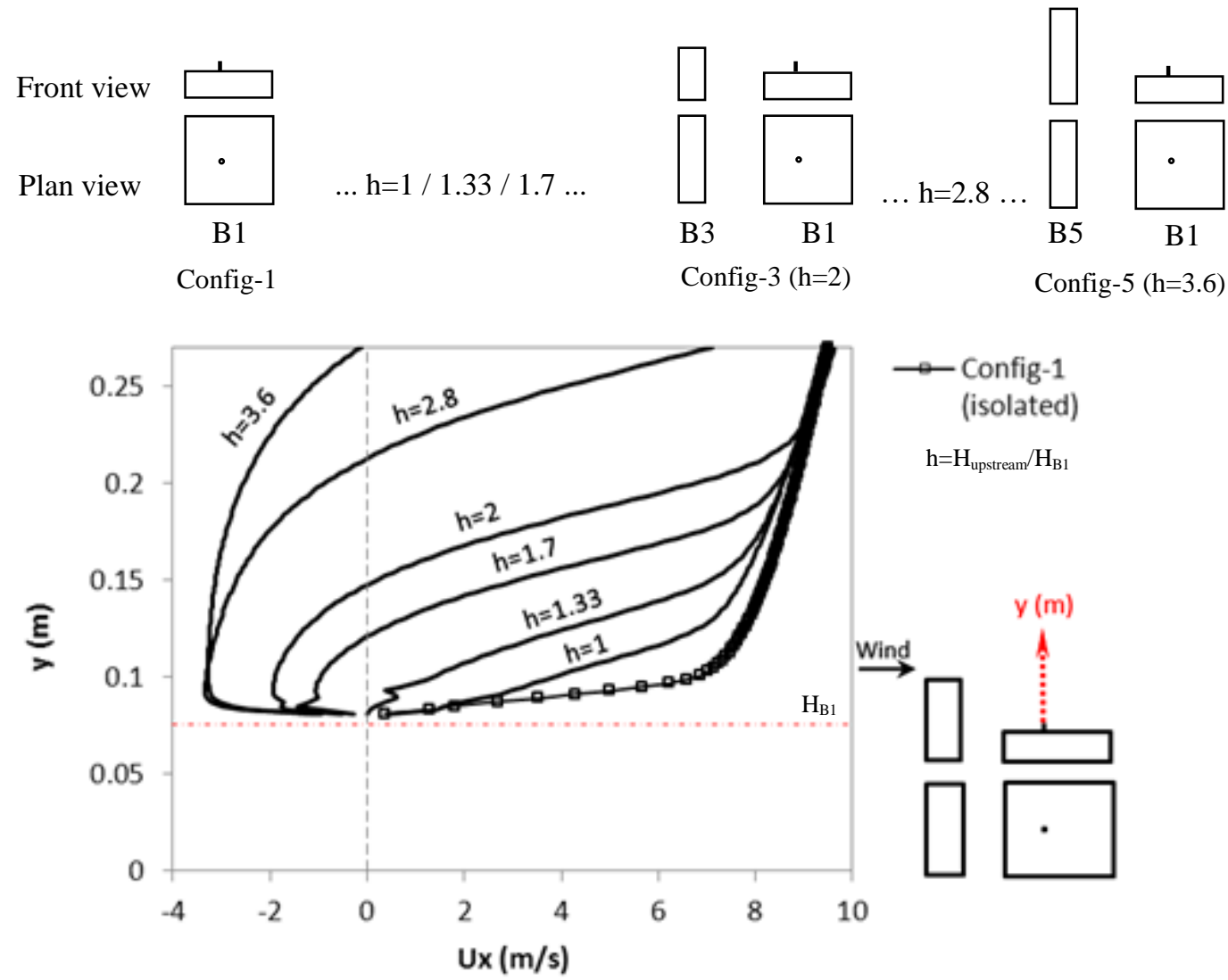

Figure 7. Velocity profile, $\mathrm{Ux}(\mathrm{m} / \mathrm{s})$ along the indicated plotting line. Effect of upstream building height, using Realizable $\mathrm{k}-\varepsilon$ turbulence model with $\mathrm{Sc}_{\mathrm{t}}=\mathbf{0 . 7}$.

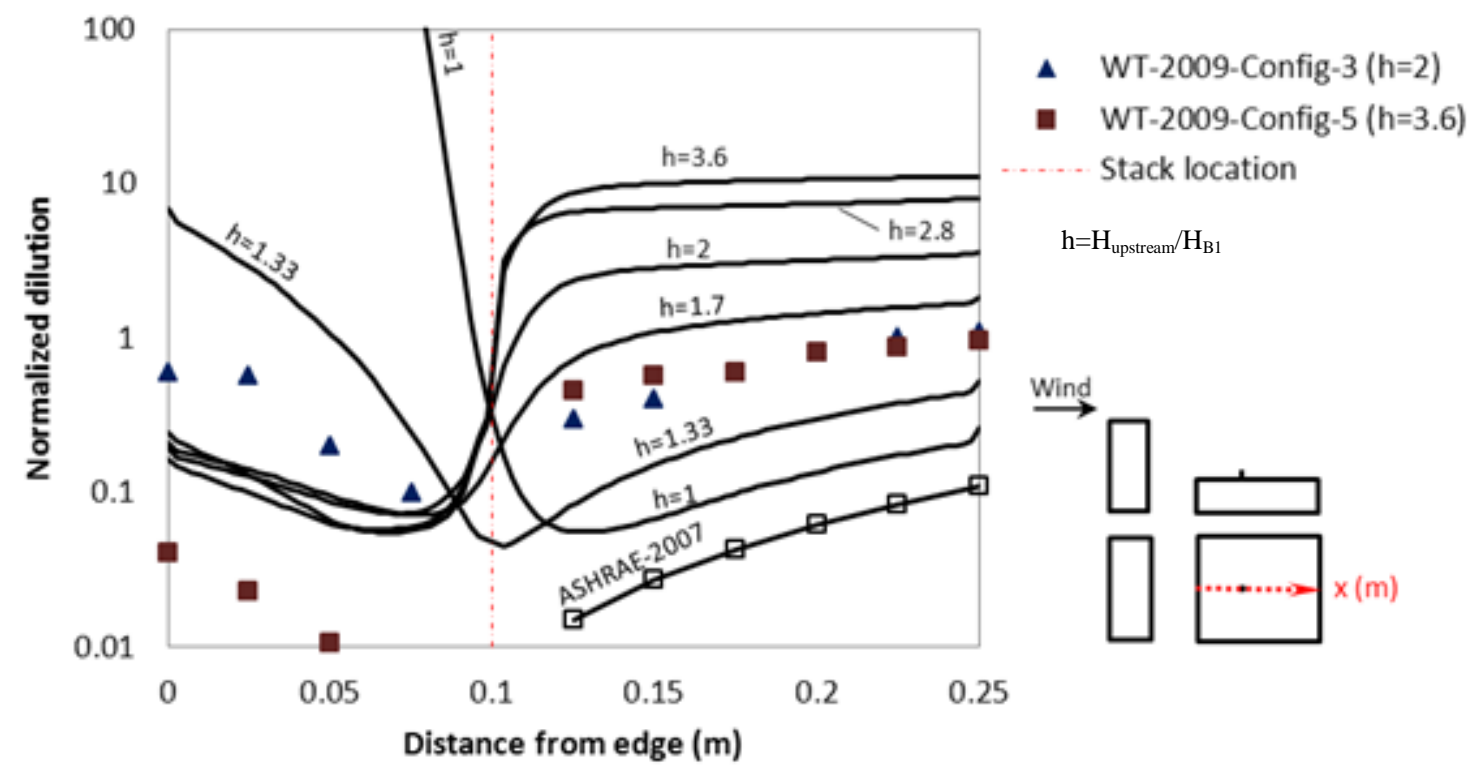

Figure 8. Effect of upstream building height on dilution on the roof of B1. All cases consider stack height $=0.005(\mathrm{~m})$ and $M=1$ (exhaust momentum). 


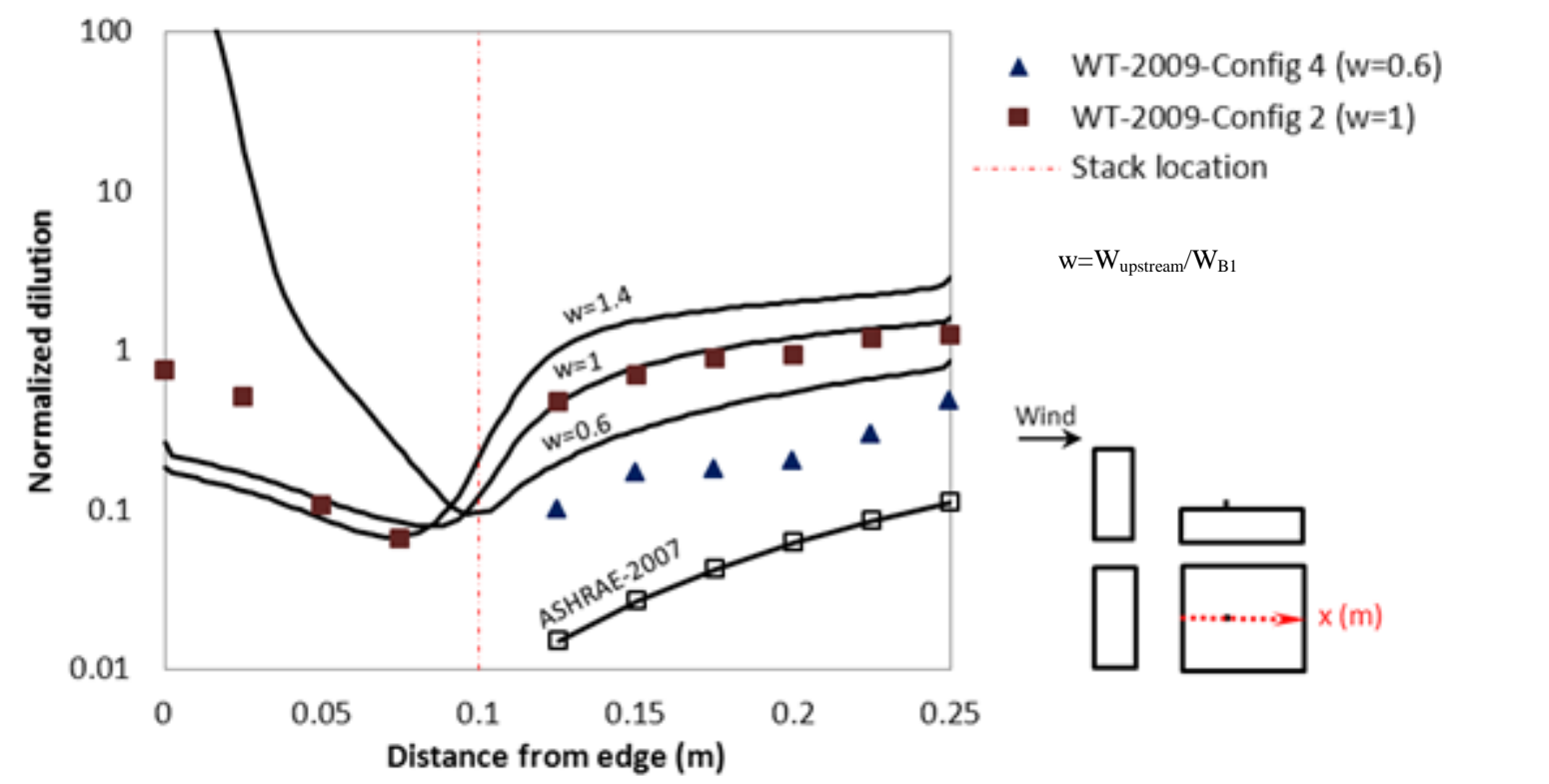

Figure 9. Velocity profile, $\mathrm{Ux}(\mathrm{m} / \mathrm{s})$ along the indicated plotting line. Effect of upstream building width, using Realizable $\mathrm{k}-\varepsilon$ turbulence model with $\mathrm{Sc}_{\mathrm{t}}=\mathbf{0 . 7}$

Figure 10. Effect of upstream building width on dilution on the roof of B1. All cases consider stack height $=0.005(\mathrm{~m})$ and $M=1$ (exhaust momentum). 


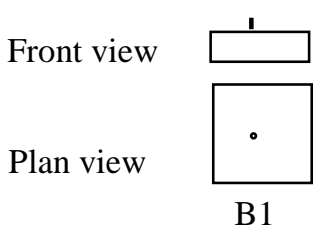

Config-1

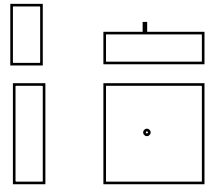

B3
B1

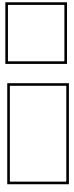

B2

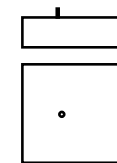

... $1=0.9$

Config-2 (l=0.6)

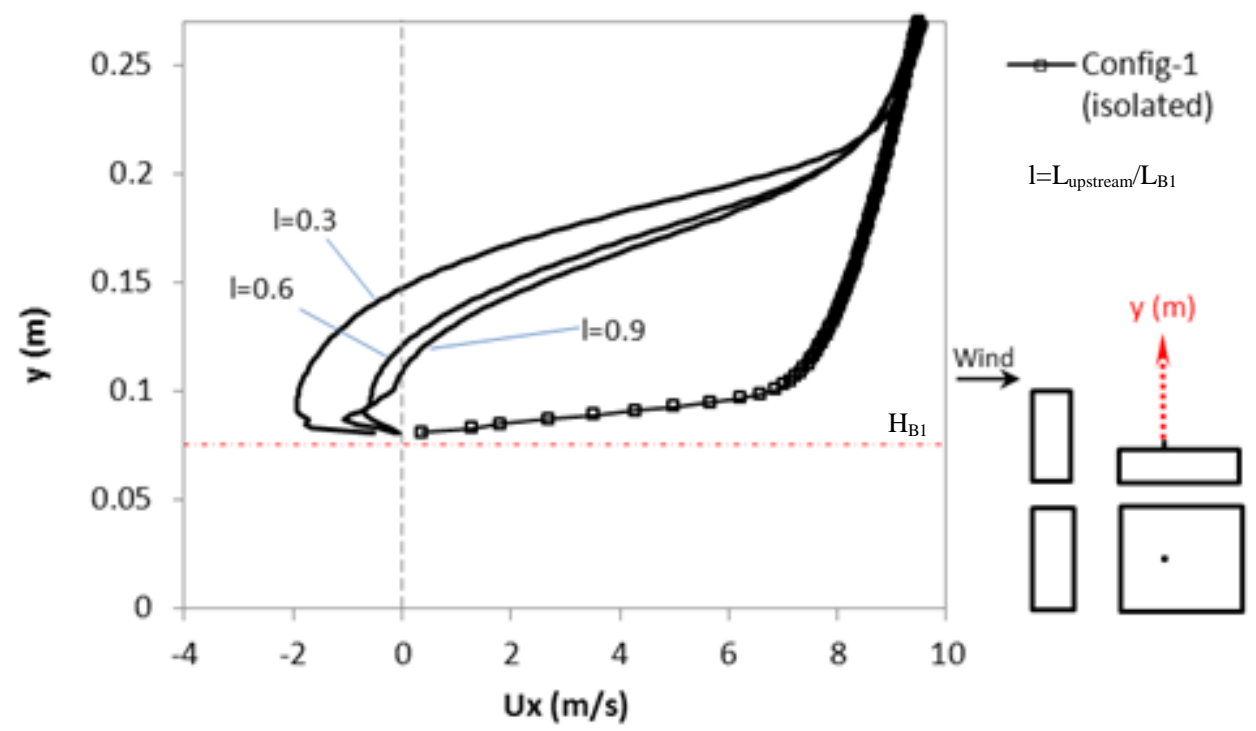

Figure 11. Velocity profile, $U x(\mathrm{~m} / \mathrm{s})$ along the indicated plotting line. Effect of upstream building length, using Realizable $\mathrm{k}-\varepsilon$ turbulence model with $\mathrm{Sc}_{\mathrm{t}}=\mathbf{0} .7$.

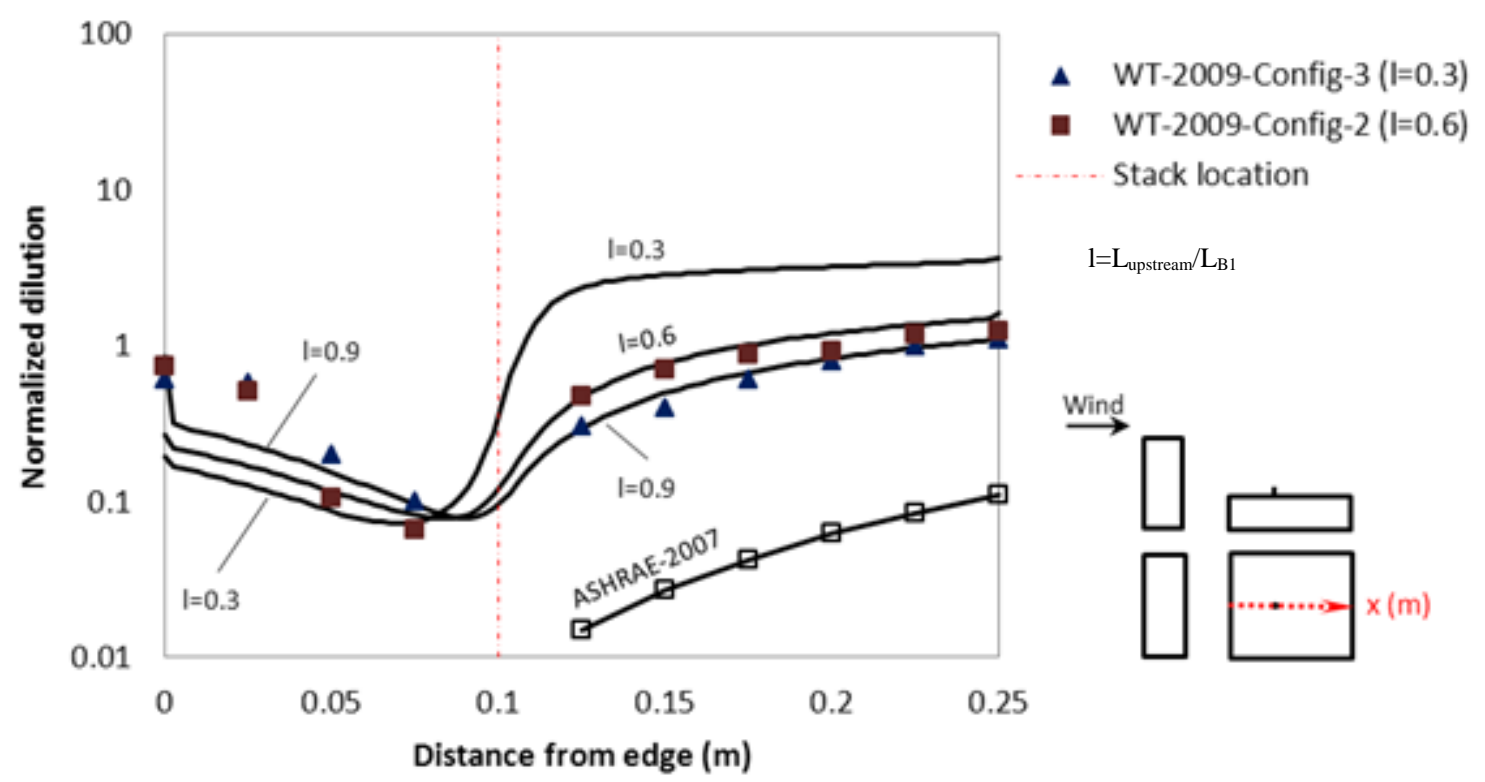

Figure 12. Effect of upstream building length on dilution on the roof of B1. All cases consider stack height $=0.005(\mathrm{~m})$ and $M=1$ (exhaust momentum). 
Table 1. Building models for CFD and wind tunnel experiments

807

\begin{tabular}{|l|l|l|l|}
\hline Building & Height, H (m) & Width , W (m) & Length, L (m) \\
\hline B1 (emitting building) & $0.075(15)$ & $0.25(50)$ & $0.25(50)$ \\
\hline B2 & $0.15(30)$ & $0.25(50)$ & $0.15(30)$ \\
\hline B3 & $0.15(30)$ & $0.25(50)$ & $0.075(15)$ \\
\hline B4 & $0.15(30)$ & $0.15(30)$ & $0.15(30)$ \\
\hline B5 & $0.27(54)$ & $0.25(50)$ & $0.075(15)$ \\
\hline
\end{tabular}

808

NB: Width refers to across wind dimension

809

810

811 